\title{
II. LA REVOLUCIÓN FRANCESA, SU DECLARACIÓN DE DERECHOS Y EL CONSTITUCIONALISMO IBEROAMERICANO *
}

\author{
ANTONIO COLOMER VIADEL \\ Profesor Titular de Derecho Constitucional \\ Universidad Autónoma de Madrid \\ Vicepresidente de la Academia Internacional \\ de Derecho Constitucional
}

* XIII ${ }^{\circ}$ CONGRÉS INTERNATIONAL DE DROIT COMPARÉ. Montreal (Canadá), 19 au 24 août 1990.

SÉANCE IV B. DROIT CONSTITUTIONNEL 

Revista de Derecho Político, núm. 34, 1991, pp. 355-368

\title{
II. LA REVOLUCIÓN FRANCESA, SU DECLARACIÓN DE DERECHOS Y EL CONSTITUCIONALISMO IBEROAMERICANO
}

\author{
POR \\ ANTONIO COLOMER VIADEL \\ Profesor Titular de Derecho Constitucional \\ Universidad Autónoma de Madrid \\ Vicepresidente de la Academia Internacional \\ de Derecho Constitucional
}

\section{INTRODUCCIÓN}

En 1795 el criolio Antonio de Nariño traduce e imprime, en Bogotá, la Declaración Universal de los Derechos del Hombre y del Ciudadano que alcanza, de inmediato, una enorme difusión.

Esta influencia francesa es innegable (aunque también es un ejemplo muy vivo el proceso de la independencia norteamericana y las ideas constitucionales que de ella nacen), así como el espíritu del liberalismo naciente en las Cortes de Cádiz de 1812 a las que asisten diputados peninsulares y americanos, súbditos de la Corona española.

Incluso los más entusiastas defensores de la vinculación del proceso emancipador iberoamericano al modelo de 1789 no dejan de expresar modulaciones y diferencias sobre ese modelo que son bien significativas.

Uno de los autores más apasionados defensores de esa influencia es el chileno Francisco BILBAO en cuyo «Evangelio americano» se considera a la revolución de la independencia a imagen de la Revolución norteamericana y, sobre todo, de la Revolución francesa. «El pensamiento de la revolución... contenía la independencia del territorio, la soberanía del individuo, la soberania del pueblo, la forma republicana de gobierno, el advenimiento de la democracia desde la aldea hasta las capitales, la separación de la Iglesia del Estado... la libertad de cultos y la libertad de 
industria, la comunicación con el mundo... la igualdad de las razas, reconociendo sus derechos a la tierra que poseen». BILBAO identifica, enseguida, cuál es el origen de estas ideas. «Nuestra revolución, con pasado o porvenir, ha salido de la "Edad Nueva" de la Europa. La Edad Nueva estalló en Francia; luego eslabonemos nuestro pensamiento revolucionario al pensamiento francés de la revolución». Y más adelante: «el espectáculo de la renovación francesa era esplendoroso para no alcanzar algún tanto de su luz. La revolución germinaba entre nosotros y estalló a la señal de la prudencia» 1 .

Sin embargo, como decíamos, existe un punto profundamente contradictorio con el modelo jacobino centralista, igualitario y unificador, ya que Bilbao defiende "la independencia de todos los intereses y derechos locales en lo relativo a sus localidades; movimiento federalista en un principio anulado después por la reacción unitaria en toda Amércia y que hoy vuelve a continuar triunfante».

Es curioso observar cómo el proyecto de MIRANDA, impregnado de ideas afrancesadas, defiende también una tesis comunera y federalista que organizaba a toda la América hispana en una federación de municipios libres. Miranda logró imponer la declaración de independencia de las Provincial Unidas de Venezuela - 5 de julio de 1811 -, base de la Constitución republicana de Ustáriz -21 de diciembre de 1811-, y cuyo empeño en adaptarse al modelo francés fue incluso rechazado por Bolivar.

No existe, pues, una única influencia pese a la pretensión de algunos autores, sino una variedad de soluciones que iban desde una monarquía sin Rey -la pretensión de gobernar en nombre de Fernando VII- hasta la posibilidad de establecer varias monarquias con nuevos príncipes, o dictaduras democráticas encarnadas por algunos de los grandes libertadores. Lo cierto es que el desprestigio de la Monarquía española se acentúa ante la actitud antiliberal de Fernando VII que deroga la Constitución de 1812 y emprende una persecución de los liberales. La opción republicana se refleja claramente en los Congresos de Apatzingan 1814; Tucumán, 1816, y Angostura, 1819.

Existía una contradicción entre la posición de los liberales españoles, centralizadores y unitarios, y sus compañeros americanos, mucho más defensores de la autonomía local y los rasgos diferenciales.

Al mismo tiempo se produce una paradójica reacción en las luchas por la independencia americana de los antiguos reinos de la Corona española, vinculada a los avatares de la causa liberal en la península. Así la restauración en España de la Constitución de Cádiz, en 1820, llevó hacia

Francisco BILBAO: El Evangelio americano y páginas selectas. Barcelona, Ed. Maucci (s.a.). Citado por Jaime Delgado, La Independencia Hispanoamericana, I.C.H., Madrid 1960, pp. 38-41. 
posiciones independentistas a los sectores conservadores que se mantenían fieles a la Corona y habian mantenido libres de insurgentes a Perú y México ${ }^{2}$.

Al mismo tiempo el papel que desempeñan en estas guerras de independencia los caudillos locales - cuya presencia va a ser constante en la historia iberoamericana- y las dificultades estructurales de organizar un Estado unitario y eficazmente organizado, favorecerá las tensiones desintegradoras, el reconocimiento de tesis federalistas o seudofederalistas y un crecimiento excesivo del Poder Ejecutivo y la figura de los presidentes - para compensar las tendencias de dispersión y fraccionamiento-que caracterizan de forma peculiar y genuina al naciente Estado iberoamericano $^{3}$.

Sin embargo es en el análisis de algunas instituciones concretas en donde podemos encontrar las huellas más evidentes del espíritu de 1789, aunque siempre entremezcladas de posiciones contradictorias.

\section{LA INFLUENCIA FRANCESA EN ALGUNAS INSTITUCIONES CONSTITUCIONALES IBEROAMERICANAS}

En la etapa constituyente de los nuevos Estados se cita, con frecuencia, como argumento de autoridad las ideas de Rousseau y Montesquieu, así como se maneja con soltura la Declaración de Derechos del Hombre de 1789, traducida de inmediato por Nariño, como ya dijimos.

Los textos de las Constituciones francesas de 1793 y 1795 son también conocidos y utilizados y, en algún caso, traducidos para ser incluidos literalmente algunos artículos en textos constitucionales americanos ${ }^{4}$.

2 Jaime Delgado, op. cit., pp. 108-110. Sobre las posiciones de los liberales españoles y americanos durante las Cortes de Cádiz, véase Julia SeVILLA MERINo: Las ideas internacionales en las Cortes de Cádiz, Facultad de Derecho, Valencia 1977. En especial, el capítulo IV.

3 Sobre esta cuestión, véanse nuestros Cursos en l'Académie Internationale de Droit Constitutionnel, Antonio Colomer VIADEL: L'État-Nation dans le monde iberoaméricain, Túnez 1988, y «La valeur du fait constitutionnel dans les États iberoaméricains", en la obra La Suprématie de la Constitution, Les Ed. Tobkal, Casablanca 1987.

4 José MIRANDA: Las ideas y las instituciones politicas mexicanas, UNAM, Inst. de Derecho Comparado, México 1952. El autor establece este claro origen, respecto a la Constitución mexicana de 1814, p. 362. 
Conviene, sin embargo, fijarse en algunas instituciones por su significación para determinar la fórmula constitucional y la filosofía política en que se sustenta. La idea de soberanía, la división de poderes y la defensa de los derechos parecen responder a ese sistema sin el cual, de acuerdo con la famosa formulación del artículo 16 de la Declaración de Derechos del Hombre y del Ciudadano, no existe Constitución.

\section{La soberanía}

La convicción de que los valores de la libertad y de la igualdad eran incompatibles con el despotismo está profundamente difundida en la hora emancipadora de América.

Al mismo tiempo la influencia de Rousseau va a hacer que sobre el concepto de soberania se polarice gran parte del debate constituyente, a la vez que se va a bifurcar el constitucionalismo iberoamericano entre los que son fieles a la idea de la soberanía popular, no delegable porque esencialmente siempre permanece unida a su titular, el pueblo -que es la posición de México-, y aquellos que asumirán la nueva doctrina, diseñada por Sieyes, de la soberania nacional, íntimamente vinculada al principio de representación política y al concepto moral y abstracto de nación, que es la posición constitucional de Argentina y otros países.

En México los primeros textos constitucionales y las obras doctrinales que los fundamentan parten de esta concepción de la soberania, hija de la idea roussoniana de la imposibilidad de representar la voluntad general en cuerpos constituidos. A los representantes sólo se les cede temporal y revocablemente el ejercicio de esa soberania que queda vinculada al pueblo.

En la obra de MORELOS Sentimientos de la nación, dirigida al Congreso de Chilpancingo, el 14 de septiembre de 1813, el punto quinto declara: "la soberanía dimana inmediatamente del pueblo, el que sólo quiere depositarla en sus representantes...".

La que se va a llamar Constitución de Apatzingán, primer texto constitucional mexicano, de 1814, refleja también esta idea de la soberanía popular como fuente del sistema representativo. En su artículo quinto se señala que "reside... su ejercicio en la representación nacional compuesta por diputados electos por los ciudadanos». Y su artículo 18 expresa, con un estilo plenamente roussoniano, que «la Ley es la expresión de la voluntad en orden a la felicidad común...". Otro reflejo de las ideas del filósofo ginebrino se encuentra en el artículo 24 , al abrir la materia sobre regulación de las libertades, "la felicidad del pueblo y de cada uno de los ciudadanos consiste en el goce de la igualdad, seguridad, propiedad y libertad. La ín- 
tegra conservación de estos derechos es el objeto de la institución de los gobiernos y el único fin de las asociaciones políticas».

Si la soberania reside en la nación y no en el Congreso de acuerdo con esta tradición constitucional, la soberanía será un poder del pueblo "para darse la organización politica que le convenga y la facultad de preservar este poder como suyo para modificar su estructura estatal, de acuerdo con sus decisiones en todo el curso de su destino" ${ }^{5}$.

Esta concepción de la soberania ha inspirado, a pesar de crisis y reformas, la evolución del constitucionalismo mexicano.

El proyecto de Acta Constitutiva de la Federación, pesentado al Congreso constituyente de 20 de noviembre de 1823, en su artículo tercero señalaba: «La soberanía reside radical y esencialmente en la nación, y por 10 mismo pertenece exclusivamente a ésta el derecho de adoptar y establecer por medio de sus representantes la forma de gobierno y demás leyes fundamentales que le parezcan más convenientes para su conservación y mayor prosperidad, modificándolas o variándolas, según crea convenirle más».

Después de las Leyes constitucionales de 1836, que no niegan la soberanía pero no la desarrollan, ya que no interesa a los intereses oligárquicos dominantes, y de la dictadura del general Santa Anna, la Constitución de 1857, o Constitución de la Reforma, va a establecer nítidamente el concepto de soberania en su artículo 39: «La soberanía nacional reside esencial y originariamente en el pueblo. Todo poder público dimana del pueblo y se instituye en su beneficio. El pueblo tiene en todo momento el inalienable derecho de alterar o modificar la forma de su gobierno".

Este artículo sobre la soberanía, reforzado, además, por la implantación del sufragio universal, va a perdurar en la evolución constitucional mexicana hasta nuestros dias. Los comentaristas de la Constitución de 1857, y especialmente Castillo Velasco y Coronado, defienden la interpretación de la permanencia de la soberanía en el pueblo que es distinto a delegar su ejercicio en los representantes. Por ello sobre la supremacia de la Constitución está la soberanía del pueblo, su autor ${ }^{6}$.

Esta distinta concepción de la supremacía constitucional también será un punto de divergencia entre la interpretación más formalista del derecho propia de la concepción de soberanía nacional, arraigada, como veremos, en los países del Cono Sur americano y aquellos otros influidos por la idea de soberanía popular en el Derecho Constitucional mexicano.

5 Miguel DE LA MADRID: «La soberania popular en el constitucionalismo mexicano y las ideas de Rousseau», en Estudios de Derecho Constitucional, México 1981, 2. ${ }^{a}$ ed., p. 142.

I Ibidem, pp. 154 y ss. 
La revolución mexicana de 1917 asumió esta concepción de la soberanía de los artículos 39,40 y 41 de la Constitución de 1857, y consideró a la misma el fundamento del cambio de la estructura social y económica, reflejada en los derechos y garantías sociales de la Constitución de 1917.

Por ello a pesar de algunas dudas sobre cierto carácter dualista de la soberanía debido al principio federal, y el problema de la interpretación del artículo 136 de esta Constitución que declara inviolable la Constitución - pero se interpreta no como límite al pueblo y su poder constituyente sino a facciones que desconozcan la voluntad popular-, predomina la interpretación enunciada por Miguel DE LA MADRID: “La soberanía popular, dentro de la corriente doctrinal en que se inspira el constitucionalismo mexicano, siempre es una potestad inseparable de la nación; nunca puede convertirse en atributo de la comunidad en cualidad del orden jurídico, y menos aún en adjetivo de las funciones gubernamentales»?

Aunque la práctica política desvirtúa en ocasiones tan radicales enunciados, lo cierto es que, en el orden de los principios, es mantenida con rigor.

En esta vieja polémica sobre la soberanía popular y la soberania nacional, a favor de la última y del concepto liberal burgués de Constitución que señala a la soberanía como pertenencia de la persona moral abstracta que es la Nación, distinta al pueblo que la forma, y sólo operante a través de los representantes de esa persona moral, se encuentra la posición de la Argentina.

La Constitución argentina de 1856 asume la actitud más radical sobre el carácter estricto de la democracia representantiva, excluyente de toda participación popular que no sea a través de delegación y por tanto fiel a este concepto clásico de soberanía nacional. El artículo 22 de la Constitución afirma: «El pueblo no delibera ni gobierna sino por medio de sus representantes y autoridades creadas por esta Constitución». La capacidad del pueblo se resume, pues, en la elección de aquellos miembros de los órganos de poder que realizarán las funciones también presentes en la Constitución ${ }^{8}$.

El temor del constituyente argentino a que este modelo pudiera modificarse le llevó a una increíble redacción del segundo párrafo de este articulo, que en una interpretación estricta cierra el paso a un derecho de tanto arraigo como el de petición: «Toda fuerza armada o reunión de personas que se atribuya los derechos del pueblo y peticione a nombre de éste, comete delito de sedición». Tal exageración ha llevado a comentar al profesor SÁNCHEZ VIAMONTE que «es evidente que no hay sedición cuan-

7 Miguel DE LA MADRID: “La soberanía popular...", op. cit., p. 166.

- Antonio Colomer VIadel: La Suprématie de la Constitution, op. cit., p. 301. 
do se peticiona porque no se arroga ningún poder y mucho menos un poder soberano, quien peticiona, pide o ruega» ${ }^{9}$.

Se pretendia de este modo salvaguardar la forma de gobierno de la república representativa y resistir los intentos de asalto o apropiación de la soberanía nacional. Esta disposición fue imitada en numerosas Constituciones (véase el artículo $4 .^{\circ}$ de la Constitución de Costa Rica o el artículo 2, párrafo segundo, de la reciente Constitución de Honduras, 1982, en otros ejemplos).

Queda en pie la cuestión de si el pueblo podria rebelarse contra gobernantes que abusen del poder o se desvíen de los fines constitucionales. El clásico derecho de «resistencia a la opresión» que establecia el artículo $3 .^{\circ}$ de la Declaración Francesa de los Derechos del Hombre y del Ciudadano.

Ante este problema fundamental de ética política -hemos escrito en otro lugar ${ }^{10}$ - la respuesta del constitucionalismo argentino es el arquetipo del axioma juridico de la superioridad formal de la Constitución, y la consagración, sin fisuras, de los dogmas de la democracia representativa, y la soberanía nacional estricta. El artículo $29,1 .^{\circ}$, correlacionado con el 21, podría suponer este reconocimiento del Derecho - en forma de deber- de resistir a la opresión: «todo ciudadano argentino está obligado a armarse en defensa de la Patria y de esta Constitución...». Sin embargo todo ello resulta condicionado por las palabras que siguen a las transcritas: «... conforme a las leyes que al efecto dicte el Congreso y a los decretos del Ejecutivo nacional». De lo que se infiere que si no se dictan tales leyes ni los correspondientes decretos del Ejecutivo, «faltarían los elementos jurídicos indispensables para poner en movimiento la prescripción constitucional».

Nos encontramos, pues, ante el desiderátum jurídico del concepto burgués del mandato representativo que conviene juzgar en el contexto oligárquico de mediados del siglo XIX, apoyado por el voto censitario como salvaguarda de sus intereses.

\section{La división de poderes}

El constitucionalismo iberoamericano refleja la influencia de dos modelos inspiradores también en esta institución de la división de poderes y la forma de gobierno: una, la de la Constitución norteamericana, que com-

9 Carlos SAnchez Viamonte: El Constitucionalismo. Sus problemas, Buenos Aires 1957, pp. 563-6.

10 Antonio Colomer Viadel, op. cit., p. 302. 
bina división de poderes y régimen presidencial; otra, la del constitucionalismo francés originario, de claro predominio de la cámara legislativa.

Resulta una exageración el atribuir a Montesquieu la teoría de la división de poderes, ya que él pretendió que no existiera confusión del poder al concentrarlo en un solo órgano, pero la idea de tres órganos con poderes soberanos es obra de los exégetas e intérpretes no muy fieles de la teoría política del barón de La Brede y Montesquieu.

La dificultad se hace aún mayor si se intenta combinar tal organización de los poderes con la idea de la soberanía de Rousseau, de naturaleza esencialmente indivisible.

El conflicto entre indivisibilidad de la soberanía y división de poderes se resolvió en las Constituciones francesas de 1793 y 1795 a favor de un predominio de la asamblea única, órgano legislativo al que estaba claramente sometido el Ejecutivo. Claro está que la Constitución del 93 no rigió en la práctica, dominada por la época del terror y la dictadura de Robespierre.

Este modelo va a influir claramente en el primer constitucionalismo iberoamericano. En la Constitución mexicana de Apatzingán los constituyentes utilizaron frecuentemente los textos constitucionales franceses de 1793 y 1795 y la Constitución española de 1812 que influyó en el sistema electoral ${ }^{11}$.

En el Reglamento del Congreso, dado por Morelos en Chilpancingo el 11 de septiembre de 1814, se preserva la división de los poderes al señalar su artículo 13 que "tan luego se integrara el Congreso Constituyente, procederia en su primera sesión a la distribución de poderes, reteniendo únicamente el que se llama legislativo».

En el punto quinto, «De los sentimientos de la Nación», obra de MORELOS, que ya citamos en relación al concepto de soberanía, se señala: "La soberanía dimana inmediatamente del pueblo, el que sólo quiere depositarla en sus representantes dividiendo los poderes de ella en legislativo, ejecutivo y judiciario...".

La Constitución de Apatzingán refleja el axioma de distribuir el ejercicio de la soberania entre tres órganos distintos, evitando su concentración en uno solo de ellos.

$"$ José Miranda, op. cit., pp. 362 y ss. 
Se intenta en este momento fundacional y constituyente resolver la vinculación entre una soberanía popular imprescriptible, inenajenable e indivisible - según señala el artículo tercero-con el funcionamiento de diferentes poderes constitucionales. Así el articulo segundo dice que "soberanía es la facultad de dictar leyes y de establecer la formá de gobierno que más convenga a los intereses de la sociedad". «Este poder constituyente popular puede alcanzar hasta "abolir" totalmente el gobierno según le convenga» (art. $4 .^{\circ}$ ).

En esta misma Constitución el artículo 12 indica que «estos tres poderes, legislativo, ejecutivo y judicial, no deben ejercerse ni por una sola persona, ni por una sola corporación». De acuerdo con este mandato constitucional, la estructura de las tres potestades quedan configuradas por un Supremo Congreso mexicano, órgano legislativo representante de la soberanía, formado por un diputado de cada provincia, hasta que funcione la Representación Nacional, una vez liberados los territorios; un Supremo Gobierno, constituido por tres individuos designados por el Congreso, alternándose en la presidencia cada cuatro meses, por sorteo, en el Congreso, y tres secretarios, de Guerra, Hacienda y Gobierno; y un Supremo Tribunal de Justicia, constituido por cinco individuos, designados por el Congreso y que también ejerce la presidencia rotativamente cada tres meses, por sorteo celebrado en el Congreso.

Este modelo constitucional está claramente influido por el de la Constitución francesa de 1795 que también preveía un Ejecutivo colegiado y rotatorio: el Directorio de cinco miembros. El Supremo Gobierno mexicano y el Directorio francés carecen igualmente de iniciativa legislativa. El claro predominio del Congreso mexicano se manifiesta además en la reserva a su favor de las facultades de control de la guerra y la paz, así como la dirección de las relaciones internacionales (arts. 108, 110, 111 y 112). Una facultad de gran trascendencia reservada al Congreso por el artículo 107 es la de resolver las dudas de hecho y de derecho que se ofrezcan en orden a las facultades de las Supremas Corporaciones. De esta forma el Congreso ejerce el control de la constitucionalidad.

Bien significativo de esta supremacia del Congreso es que las tropas de guarnición estaban bajo sus órdenes (art. 47) a la vez que los miembros del Supremo Gobierno tenían prohibido mandar fuerza armada alguna (art. 168).

Resultan también curiosas las limitaciones impuestas a las Corporaciones Ejecutiva y Judicial que no podian alejarse de la residencia del Congreso, si no cuando éste lo acordase y a la distancia fijada por él (art. 45). De igual modo ningún individuo del Supremo Gobierno o del Supremo Tribunal de Justicia podían pasar ni una sola noche fuera del lugar destinado a la residencia sin permiso del Congreso (arts. 141 y 193).

El Congreso y el Tribunal Supremo disponían únicamente de un débil veto suspensivo sobre las leyes, ya que si el Congreso no considera aten- 
dibles sus observaciones - presentadas en los veinte días siguientes a la aprobación de las leyes- se publican éstas tal y como las aprobó el Congreso.

Nos encontramos, de forma manifiesta, ante un régimen Convencional o de Asamblea, con profundas semejanzas organizativas con los regímenes de Francia en 1793 y, sobre todo, 1795.

Sin embargo, este modelo tendrá poca influencia posterior, aunque algún constitucionalista mexicano apunta cierta tendencia congresional de la Constitución de 1857, algo dudosa, y tal vez más evidente en el caso de la Convención Revolucionaria de Aguascalientes, en $1914^{12}$.

La evolución del régimen político mexicano ha sido el fortalecimiento del Ejecutivo y, de forma significativa, de la Presidencia de la República.

La evolución del pensamiento constitucional mexicano, a partir de la idea de que no hay división de poderes sino que existe un solo poder, se concreta en el artículo $49-1 .^{\circ}$ de su vigente Constitución: «El Supremo Poder de la Federación se divide, para su ejercicio, en legislativo, ejecutivo y judicial". Esta norma refleja la antigua reflexión sobre la soberanía indivisible y el ejercicio plural de la misma. Cada rama del poder es creada por la propia Constitución que le señala expresamente sus facultades. Pero, además, comentan los profesores CARPIZO y MADRAZO, la propia Constitución construye la colaboración entre las ramas del poder: intervención del Presidente en el legislativo mediante la iniciativa de leyes, el veto y la publicación de las leyes; la aprobación por el Senado de numerosos nombramientos de funcionarios; el Presidente puede pedir ante la Cámara de Diputados la destitución por mala conducta de cualquier miembro de la Corte Suprema de Justicia y otros jueces ${ }^{13}$.

Esta erosión del principio de división de poderes se agrava por medio de la posibilidad de conceder facultades extraordinarias al Presidente para legislar, por razones de emergencia del país. Una adición al artículo 49 de la Constitución trataba de impedir que se concedieran tales facultades en tiempos normales de paz. Sin embargo, el segundo párrafo del artículo 131 - creado en 1951- establece facultades extraordinarias conferidas al Presidente por el Congreso, en materia económica y social, y termina con una fórmula amplisima: «... y realizar cualquier otro propósito en beneficio del país".

Tal situación constitucional llega a una verdadera confusión de poderes, favorecida, por otra parte, por el papel del Presidente como cabeza

12 Miguel DE LA MADRID, “División de poderes y forma de gobierno en la Constitución de Apatzingán", en Estudios..., p. 203.

13 Jorge Carpizo y Jorge Madrazo: Derecho Constitucional, UNAM, México 1983, pp. 25-8. 
del partido político hegemónico y la presencia de miembros del partido, mayoritariamente, en los distintos órganos y ramas del poder.

La posición constitucional en Argentina es radicalmente distinta, ya que el artículo 29 de su Constitución prohibe la concesión de facultades extraordinarias por el Congreso al Ejecutivo y declara la nulidad insanable de tales actos y sujeta a los que intervengan en ellos a la pena de los traidores a la patria. Esta prohibición se extiende a las legislaturas provinciales respecto a sus gobernadores. Lo que cierra el acceso del órgano Ejecutivo a funciones legislativas.

La separación entre el Poder judicial y el Poder ejecutivo es tajantemente fijada en el artículo 95 de la Constitución argentina, fiel al principio de la división de poderes: «... en ningún caso el Presidente de la Nación puede ejercer funciones judiciales, arrogarse el conocimiento de causas pendientes o restablecer las fenecidas".

Este modelo constitucional según el cual existen tres poderes distintos e independientes entre si sin que ninguno de los poderes pueda delegar el ejercicio de funciones que le son propias, respecto a la formulación de la rígida separación de poderes que nace con el primer constitucionalismo francés y al que han sido fieles las Constituciones iberoamericanas influidas por la Argentina.

La evolución internacional hacia un crecimiento del Poder Ejecutivo y una cierta colaboración de poderes consustancial con el régimen parlamentario pero que también se ha dado en los regímenes presidenciales ha influido en la realidad latinoamericana.

Al mismo tiempo han existido razones históricas y sociales que han influido en la organización y funcionamiento del poder o poderes del Estado. La debilidad del tejido social, el papel destacado de líderes, caciques o caudillos, ha personalizado al máximo la institución de la Presidencia de la República y la ampliación por el Ejecutivo - a veces por razones de integración nacional- de los ámbitos de competencia hasta invadir parcelas propias de otros poderes.

Ello nos llevaría al análisis del fenómeno del presidencialismo iberoamericano que excedería los límites de este trabajo ${ }^{14}$.

Señalemos, finalmente, que una prueba de esta imprescindible evolución es el giro de la jurisprudencia de la Corte Suprema argentina cuyo país es un paradigma de la división de poderes. Sin renunciar al principio

${ }^{14}$ A la cuestión del presidencialismo, como rasgo constitucional del mundo iberoamericano, ha dedicado el autor varios epígrafes de las obras citadas. Véase, asimismo, del autor, «El presidencialismo iberoamericano y el Estado. Notas para el análisis de una crisis». Comunicación al IV Congreso Iberoamericano de Derecho Constitucional. Madrid, 27-30 de septiembre de 1989. 
ni aceptar su violación, ha reconocido que éste requiere una adecuación a las necesidades de la vida contemporánea, a los objetivos de expansión de las fuerzas materiales y al correlativo mejoramiento económico de la comunidad ${ }^{15}$.

Poco a poco el viejo aroma de algunos principios emanados de aqueIla Declaración universal de 1789 pareciera desvanecerse. Sin embargo, bien firmes en el espíritu y en los anhelos de estos pueblos se mantienen los valores de libertad, igualdad y fraterna solidaridad para que inspiren una vida auténticamente democrática.

15 Véase el caso «Fernández Arias», en Salvador MARía Lozada: Derecho Constitucional argeritino. Según el método de Casos. Buenos Aires 1972, tomo I, pp. $25-6$, p. 44 y ss., pp. $86-87$. 